\title{
Control, perceived control or self-efficacy as confounders in the relation between fruit and vegetable consumption and psychological disorders
}

\author{
Zayra Teresa Lopez Ixta ${ }^{1}$
}

Published online: 16 May 2018

(c) Springer-Verlag GmbH Germany, part of Springer Nature 2018

With regard to Safhafian et al. article on "Consumption of fruit and vegetables in relation with psychological disorders in Iranian adults" [1], it stands out that the authors found that there is an inverse and significant association between fruits and vegetables $(\mathrm{F} \& \mathrm{~V})$ intake and symptoms of depression, anxiety and psychological distress in Iranian women; but not in Iranian men. The authors recognized that the findings may be the result of gender differences in perceived stress or health behaviors. Nevertheless, the authors did not incorporate psychosocial factors associated with mental health in their study; as a result, their findings may be confounded by those factors. Research on stress has proven that control or perceived control as a proxy of actual control has an important impact on the resulting level of distress experienced by individuals regardless of the gender [2-4]. Thus, people with real or perceived capacity to take decisions should be expected to enjoy better mental health. In this study, the relation between high F\&V intake and women's psychological wellbeing may be due to the more control or perceived control that some women may exert on their lives, which may be reflected on their capacity to achieve what they may consider as a healthy diet. Not surprisingly, the participants with the highest intake of F\&V were more likely to be older and educated. In contrast, Iranian men's diets may not be associated with psychosocial factors, and hence, F\&V intake variation in this group did not present significant association with psychological wellbeing. Consequently, the authors'

A reply to this Letter to the Editor can be read here: https://doi. org/10.1007/s00394-018-1697-y.

This Letter to the Editor refers to the original publication available here: https://doi.org/10.1007/s00394-018-1652-y.

Zayra Teresa Lopez Ixta

zalopez@iu.edu

1 Applied Health Science, Indiana University Bloomington School of Public Health, Bloomington, USA recommendation of promoting $\mathrm{F} \& \mathrm{~V}$ intake to improve mental health is not warranted given that they did not control for direct and potentially confounding factors that may be associated with the outcome and the exposure of interest. Thus, the authors should have included measurements for variables such as perceived behavioral control, self-efficacy or actual control [5].

\section{Compliance with ethical standards}

Conflict of interest The author of this letter declares that there is no conflict of interest with relation to the reviewed article.

\section{References}

1. Saghafian F, Malmir H, Saneei P, Hassanzadeh A, Javad M, Afshar $\mathrm{H}$, Siassi F, Esmaillzadeh A, Adibi P (2018) Consumption of fruit and vegetables in relation with psychological disorders in Iranian adults. Eur J Nutr. https://doi.org/10.1007/s00394-018-1652-y

2. Dalgard O, Bahadur S, Hauff E, McCubbin M, Raza H (2006) Immigration, lack of control and psychological distress: findings from the Oslo Health Study. Scand J Psychol 47:551-558. https ://doi.org/10.1111/j.1467-9450.2006.00546.x/abstract

3. Lincoln K, Chatters L, Taylor R (2003) Psychological distress among black and white Americans: differential effects of social support, negative interaction and personal control. J Health Soc Behav 44:390-407. https://www.ncbi.nlm.nih.gov/pmc/articles/ PMC2998998/. Accessed 11 Mar 2018

4. Morandi B, Hasan NT (2004) Arab American persons' reported experiences of discrimination and mental health: the mediating role of personal control. J Counsel Psychol 51:418-428. http:// psycnet.apa.org/buy/2004-19093-005. Accessed 11 Mar 2018

5. Fishebein M, Ajzen I (2010) Predicting and changing behavior. Psychology, New York 